Conclusions Molecular profiling identifies heterogeneity in the airway microbiome of COPD patients, with dominance of pathogens routinely identified at culture. However, a precise role for bacteria in COPD remains unclear.

\section{S17 IMPACT OF COPD SEVERITY AND SPUTUM PRODUCTION ON ANTIBIOTIC RESISTANCE}

\section{doi:10.1136/thoraxjnl-2011-201054b.17}

${ }^{1} \mathrm{~S} \mathrm{~J}$ Thurston, ${ }^{1} \mathrm{G} \mathrm{C}$ Donaldson, ${ }^{2} \mathrm{~T} \mathrm{D}$ McHugh, ${ }^{1} \mathrm{~J}$ A Wedzicha. ${ }^{1}$ Academic Unit of Respiratory Medicine, UCL Medical School, Royal Free Campus, London, UK; ${ }^{2}$ Clinical Centre for Microbiology, UCL Medical School, Royal Free Campus, London, UK

Introduction Bacterial infections are a well-known trigger for exacerbations of COPD. A variety of antibiotics are regularly prescribed for this group of patients but the risk and frequency of antibiotic resistance in the COPD population is less understood. Routine culture data can be evaluated to establish resistance prevalence and patterns.

Methods Culture data were collected from the sputum samples of 293 patients in the London COPD cohort over a period of 5 years $(01 / 01 / 2006-31 / 12 / 2010)$ mean ( \pm SD) months in study 28.4 ( \pm 19.9 ); age 69.9 years ( \pm 8.9 ); predicted $\mathrm{FEV}_{1} 47.8 \%$ ( \pm 16.5 ); male gender $58 \%$; exacerbation samples $48.9 \%$; sputum producers $77.5 \%$. Identification of bacterial presence was established and where clinically indicated drug sensitivity tests (DSTs) were performed. A resistant sample was reported as any bacterial isolate resistant to at least one antimicrobial agent.

Results 92/293 (31.4\%) patients had at least one bacteria positive sample over the study period. $87 / 92(94.6 \%)$ patients had samples where DSTs were performed on bacteria positive samples. Resistance was observed in 69/87 (79.3\%) patients. 30/293 (10.2\%) patients were resistant to all samples where DSTs were performed. $227 / 293(77.5 \%)$ of patients were sputum producers. There was no significant relationship between predicted $\mathrm{FEV}_{1}$ and antibiotic resistance frequency in this cohort $\left(X^{2}\right.$-test; $\left.p=0.577\right)$. Patients who were classified as regular sputum producers were more likely to exhibit resistance in culture positive bacteria $(p=0.048)$.

Conclusion Results from this analysis conclude that an estimated $23.5 \%$ of COPD patients will develop resistance to an antimicrobial agent within 28.4 months of follow-up with sputum producers being at a higher risk. This study highlights the importance of investigating sputum samples with determination of resistance patterns. Information on resistance patterns and transmission of resistance in COPD can allow more appropriate and targeted antibiotic therapy for COPD exacerbations with improved outcomes.

\section{S18 A COMPARISON OF PREVALENCE AND LOAD OF AIRWAY BACTERIA IN COPD PATIENTS WITH PAIRED STABLE AND EXACERBATION STATE SAMPLES}

doi:10.1136/thoraxjnl-2011-201054b.18

D S Garcha, S J Thurston, A R C Patel, A J Mackay, J J P Goldring, T D McHugh, G C Donaldson, J A Wedzicha. University College London, London, UK

Introduction Airway bacterial infections are associated with COPD exacerbations. The most frequently identified bacteria in COPD are Haemophilus influenzae (HI), Moraxella catarrhalis (MC) and Streptococcus pneumoniae (SP) (Wilkinson et al, 2006), though studies have used culture techniques, with little data available on PCR methodology in airway infection. Using the London COPD cohort, we aimed to assess and quantify bacterial prevalence and load via quantitative PCR, in paired baseline and exacerbation sputum samples.
Methods Quantitative PCR was utilised, measuring prevalence and load on paired baseline and exacerbation samples, with baseline samples obtained within 1 year prior to its paired exacerbation. SP, $\mathrm{HI}$ and MC gene targets were Spn9082; Haemophilus influenzae P4 lipoprotein gene; copB outer-membrane-protein gene, respectively. The baseline state was defined as being at least 6 weeks after, and 2 weeks before, an exacerbation. Exacerbation was defined as two consecutive days of at least two increased symptoms (Anthonisen criteria), at least one of which is a major symptom (dyspnoea; sputum purulence; sputum volume).

Results Sixty-nine paired baseline and exacerbation sputum samples were obtained from 56 patients: mean $( \pm$ SD) age 71.0 years $( \pm 8.4)$; predicted $\mathrm{FEV}_{1}$ 46.4\% ( \pm 17.0 ); male gender $60.4 \%$; current smoker $30.2 \%$. Bacteria were detected at significantly higher rate at exacerbation, being seen in 36/69 (52.2\%) exacerbations, and 19/69 $(27.5 \%)$ baseline samples $\left(\chi^{2}\right.$-test; $\left.p=0.003\right)$. Mean bacterial load was significantly higher at exacerbation, with mean load of 8.3 $( \pm 1.1) \log _{10} \mathrm{cfu} / \mathrm{ml}$, compared with mean of $7.3( \pm 1.8) \log _{10} \mathrm{cfu} / \mathrm{ml}$ at baseline (paired-samples t test; $p<0.001$ ), indicating a 10-fold overall-load increase at exacerbation. MC frequency increased significantly from $4.3 \%(3 / 69)$ at baseline to $17.4 \%(12 / 69)$ at exacerbation $(p=0.014)$. Prevalence of HI $(17.4 \%$ vs $26.1 \%)$ and SP (8.7\% vs $20.3 \%$ ) showed non-significant increases. Mean loads of SP and $\mathrm{MC}$ increased significantly from baseline to exacerbation ( $p=0.048 ; p=0.008$, respectively).

Conclusion Prevalence and load of airway bacteria in COPD increases from baseline to exacerbation. This confirms that bacteria play an important role in exacerbation aetiology, implicating increasing bacterial load as a key underlying mechanism, and emphasises the importance of prompt antibiotic therapy at COPD exacerbation.

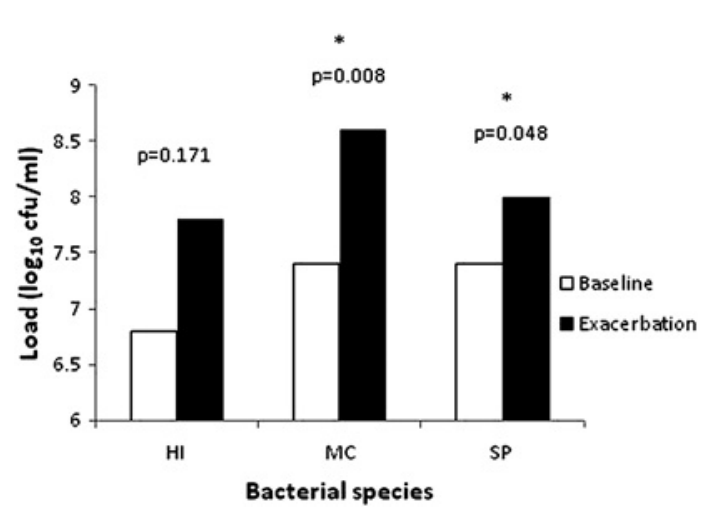

Abstract S18 Figure 1 Bacterial load at baseline and exacerbation of COPD as determined by quantitative PCR.

\section{S19 MOLECULAR FINGERPRINTING AND METAGENOMIC ANALYSIS REVEALS A POLYMICROBIAL ELEMENT IN PATIENTS WITH CHRONIC OBSTRUCTIVE PULMONARY DISEASE}

doi:10.1136/thoraxjnl-2011-201054b.19

${ }^{1} \mathrm{P} J$ Purcell, ${ }^{1} \mathrm{~A}$ Nelson, ${ }^{1} \mathrm{~A}$ Fisher, ${ }^{2} \mathrm{~J} \mathrm{D}$ Perry, ${ }^{3} \mathrm{~A}$ De-Soyza, ${ }^{1} \mathrm{~S}$ P Cummings. ${ }^{1}$ Northumbria University, Newcastle upon Tyne, England; 'Freeman Hospital, Newcastle upon Tyne, England; ${ }^{3}$ Newcastle University, Newcastle upon Tyne, England

Introduction and objectives Chronic obstructive pulmonary disease (COPD) patients commonly exhibit a multi-factorial pathology with neutrophilic inflammation and chronic obstructive bronchiolitis. COPD patients suffer episodes of pulmonary exacerbations. The role of bacteria in exacerbations has been investigated in COPD using culture-dependent techniques. Unlike cystic fibrosis (CF), there are few molecular studies describing the possibility of a 